\title{
COMUNICAÇÃO
}

\section{ASPECTOS DA HISTERIA DURANTE O PROCESSO DE ADMISSÃODA IDENTIDADE HOMOSSEXUAL}

\author{
Carla Beatriz de SOUZA, D.Sc.
}

\begin{abstract}
RESUMO
Este trabalho procurou, a partir da articulação entre a psicanálise e um texto literário interrogar a respeito de alguns sinais característicos da histeria que parecem manifestar-see pessoas em conflito por sentirem-se pressionadas a assumir publicamente umaidentidade homossexual.
\end{abstract}

Palavras chave: Homossexualidade, homossexualidade masculina, identidade homossexual, histeria

\begin{abstract}
This paper, through the intercession between psychoalysis and literature, asked about the conection of some hytericalsignals that can be present in people that are facing any strain in order to take over a homosexual identity.
\end{abstract}

Key words: homosexuality, male homosexuality, homosexual identity, hysteria.

A homossexualidade sempre esteve presente em escritos literários. Apesar, contudo, da aura de sucesso que circunda esta literatura, não é preciso ir muito além de vidas como as de Proust, Gide, Wilde ou Lorca, entre muitos outros, para percebermos o equívoco desta idéia.
"O teatro sai de humanidades confirmadas", disse Garcia Lorca (1993) na peça "O público", mostrando que o indivíduo está cercado por uma obstinada solidão num universo hostil e indiferente, onde a possibilidade de redenção através do amor tem que lutar eternamente contra o fracasso e forças desumanas.

(1) Este trabalho foi apresentado no 4th. Delphi Intemational Psychoanalytic Symposium. Delfos, Grécia, 1996.

(2) Pesquisadora junto ao CNPq no Departamento de Pós-graduação em Psicologia Clínica da PUC-Campinas.

Endereço para Correspondência: Rua São Pedro, 54/71 Cambuí - Campinas - SP - CEP 13025-350 - Tel: (OXX19) 9967577 - (OXX19)258-5093 - E-mail:CBSOUZA@YAHOO.COM 
É, pois, assim, parafraseando um editor de Lorca, Harris (1993), que introduzimos este tema.

Procurar estabelecer um certo equilíbrio entre vida pública e vida privada tem sido matéria de interesse para estudiosos das mais variadas áreas. A prerrogativa fundamental da psicanálise - conhecer-se a si mesmo - tem, hoje, acrescentado às relações um tipo especial de ansiedade. Lidar com assuntos íntimos em público e vive-versa tem sido, também, marca característica desta sociedade, que tem procurado por relações autênticas com mais desejo não seja menos importante que a outra. O que ocorreu é que as exigências públicas tornaramse mais urgentes.

É predominante entre países democráticos do mundo ocidental a transformação de percepções públicas, além da criação delas próprias. Para eles, por exemplo, o conceito de "politicamente correto" tem se espalhado com mais intensidade que qualquer outra, no passado. O "quem sou eu?" -um imperativo motivado por sentimentos narcísicos, está ocupando um lugar outrora da histeria. Além disso, para muitos autores, a histeria é coisa do passado, desde que é somente de forma retrospectiva que podemos identificar casos autênticos e clássicos. Trillat (1991) por exemplo, acredita que a noção de histeria está morta.

Atualmente, têm sido mais discutidos aspectos narcisistas que outros, quando trata-se de fenômenos mentais. No caso específico da homossexualidade, isto se faz presente especificamente devido ao significado e condições da escolha de objeto.

Expressar-nos publicamente, de acordo com Sennett (1988), requer também que perguntemos: "Que tipos de expressão os seres humanos são capazes, em seus relacionamentos?" Certamente que o comportamento neurótico oferece-nos algumas respostas. Mas, além disso, como podem ser expressas as idéias de dúvida, incertezas, indefinições, de ser e não ser, simultaneamente? Em público isto pode ser inventado mas isto também pode ser um modo estruturado de enfrentar situações difíceis.

Atualmente, devido à criação de políticas de proteção aos direitos das minorias, tornou-se necessário explicitar questões privadas, ainda que, por outro lado, isto pareça estar conduzindo a todos para um individualismo mais intenso. Podemos interpretar esta contraditoriedade como uma manifestação pós-moderna e inevitável? Esta nova era, a que já nos acostumamos chamar de "pós-moderna",é vaga terminologicamente e nos confunde ainda se prestarmos atenção aos avanços e fracassos históricos que convivem lado a lado.

Neste ponto de vista, é perigoso confundir expressão pública, por um lado, e indiscrição, por outro. Freqüentemente, políticos, estrelas de cinema etc, desnudam suas adições, abusos infantis, problemas matrimoniais, além do que, fazem isto muitas vezes tentando sorrir, mesmo de corações partidos. Novamente, temos outro sintoma perigoso: compulsão a confissões públicas. Parece não haver limites ou censuras para o que pode surgir em público, uma vez que, tornou-se mais urgente compreender os assuntos como públicos e comunitários. O que ainda permanece obscuro é se estes processos de auto exposições excessivas significam pedidos de ajuda pessoais ou são desejos manifestos de mudanças na sociedade. Percebemos com freqüência as pessoas confusas quanto a isso, tentando viver no que Lasch (1987), chama de "a era da sobrevivência", e que também pode ser chamada era de trivialização das crises".

Nossa proposta de examinar a relação existente entre homossexualidade e histeria é uma conseqüência de observações clínicas. Mesmo considerando que vivemos a "era do desnudamento", da experiência clínica temos observado que pessoas com inclinações homossexuais, muitas vezes são, emocionalmente e socialmente, coagidos a admitir isto publicamente. Na maior parte das vezes isto não é 
fácil para elas. Esta razão, mais que outras, conduz pacientes à psicanálise. Mais até que o desejo de conhecer sobre suas identidades sexuais, propriamente. Isto não significa, contudo, que isso seja como um antídoto efetivo contra intolerância entre sociedades e grupos sociais minoritários. "Aceitar" o outro além das diferenças individuais pela via do princípio do "politicamente correto", entretanto, autoriza discriminações, uma vez que é organizada e está sob controle legal. O que muda é o preço. Pagamos quando discriminamos. Mas desde que observemos as regras deste novo jogo, tudo estará bem em nossas consciências e em nossos bolsos. De fato, continuamos fazendo diferenças entre homossexualidade e heterossexualidade baseados em nossos valores, às vezes éticos. Além disso, avaliamos, julgamos e, principalmente, queremos entender, já que acreditamos na existência de explicações biológicas, psicológicas ou sociológicas para a homossexualidade.

\section{"ALEXIS, OU O TRATADO DO VÃO COMBATE"}

Em 1963, Yourcenar (1971) escreveu que as reações provocadas por "Alexis" (1929) tinham, até aquela data, mostrado a "contemporaneidade" e a "necessidade" do seu trabaIho literário. A "angústia" e o "segredo", presentes no conflito entre Alexis e sua esposa, é sentido hoje. O mundo, no que diz respeito às atitudes em relação à sexualidade, tem mudado, mas não de modo genuíno.

A decisão de Alexis de deixar sua esposa, Monica, porque ele precisa aceitar sua homossexualidade é o tema do livro de Yourcenar.

"Alexis"é usado aqui como umailustração do conflito homossexual, que muitas vezes expressa-se no adulto. O material que Yourcenar usa é um excelente modo de explorar este tema, pois trata-se de uma carta-confissão, na qual o sofrimento pela identidade sexual é dire- tamente visto como muito semelhante a alguns processos da histeria.

A palavra homossexualidade é um neologismo criado em 1869 por Kardy Benkert, um médico húngaro. Interessante observar que este foi também o ano de nascimento de Gide, cujos escritos sobre homossexualidade são de seminal importância. No livro de Yourcenar o título e o subtítulo são alusões a Gide. "Alexis" foi um nome emprestado de Virgílio por Yourcenar, assim como também dele Gide havia emprestado o seu "Corydon". "Tratado do vão combate", é uma derivação de "Tratado do vão desejo", de Gide. Entretanto, Yourcenar atribui antes a Rilke que a Gide o tema que enfoca em seu livro, ainda que seja a Gide que ela atribui sua inspiração pelos temas sexuais.

Embora tenha escrito que "a existência feminina é secreta", Yourcenar escolheu um personagem masculino para representar o conflito sexual que ele enfrenta. Isto sugere uma interpretação que vai além dos sexos. A interseção da auto-percepção como homossexual é uma característica da histeria - o sofrimento causado pelo confronto com a indeterminação da própria identidade sexual - neste caso aparece quando isto torna-se objeto de domínio público. No livro de Yourcenar, Alexis escreve uma carta à sua esposa, deixando-a. E toda a carta de Alexis pode ser vista como um pedido de perdão.

Muitas vezes, desejamos ser claros e concisos e somos completamente obscuros. Este é o caso de "Alexis" que, promete ser sincero e verdadeiro, mas ao mesmo tempo admite que isto não Ihe é fácil. Ele antecipa erros ao formular seu pensamento e constantemente tem dúvidas quanto ao seu significado. Sente dificuldade em explicar sua vida e justificar seus comportamentos. Arrepende-se por não haver lhe confessado antes, mas ao mesmo tempo é grato por não tê-lo feito. Escapa, constantemente, do seu tema principal, expressando sua falta de respostas a si próprio. Sempre procurando a verdade, ele está convencido de que tem vivido na falsidade. 
Apesar de sentir-se desconectado de sua infância, ele quer descobrir os efeitos do seu passado' em sua vida atual. Mesmo acreditando que em sua existência atual não é mais do que uma sombra, ele também acredita que seu passado pode representar a sua existência presente, do mesmo modo que aqueles que estão mortos possam estar mais presentes que aqueles que estão vivos. Para Alexis, não há felicidade ou infelicidade. Seus fantasmas são parte dele e tristeza é a marca do seu ser. Alexis discute, longamente sobre a solidão de sua infância, quando muito pouco era falado e a música pode, muitas vezes, sobrepor-se aos silêncios. Alexis também alude ao prazer, à dor, ao sofrimento e à ,descoberta de sua inadequação biológica.Mas desde que as palavras suplanta":, as ações, é possível viver sem admitir-se a verdade. Ao final,.Alexis pede perdão a sua esposa, não por estar deixando-a, mas por não tê-la deixado antes. Estas são algumas idéias que desejamos tocar: indecisão, vacilação e ambigüidade são marcas características de alguns componentes da personalidade histérica. Na homossexualidade, isto parece ser expresso pela infinita preocupação com estas indecisões.

Um outro aspecto da homossexualidade que foi descrito por Dellamora (1992) é a homofobia, presente às vezes, na personalidade homossexual. Isto pode muito bem estar presente em "Alexis". Seu casamento tentou ser a negação de sua homossexualidade.

Alexis é uma voz confessando suas inclinações homossexuais. E quando faz isto, é como se falasse e visse tais inclinações como se fosse um outro. Isto faz lembrar padre e pecador,idéias e vozes que se atravessam, desconectadas dos corpos, como se fosse possível separar espírito e corpo, amor ideal e amor carnal, amor sexualizado ou não. Todos estes conceitos estão expressos no discurso de Alexis. Ele é uma voz que confunde, escapa, enfrenta, expõe e esconde seu conflito através de cada trecho de sua narrativa. Isto é o que permite a confissão: ela tem o poder de abrir e fechar, simultaneamente, expor e confinar verdades. A confissão pode perdoar a dúvida, que toca um aspecto da histeria e impede a passagem desta condição.

A associação da homossexualidade com outras neuroses, por exemplo, com a neurose obsessiva, é mais usual do que com a neurose histérica, a não ser que se trate de uma associação pejorativa, seja em relação a uma ou a outra. Entretanto, podemos identificar esta presença. Quando alguém está em processo de aceitação de sua homossexualidade, é muito difícil ser assertivo e direto assim como ocorre no processo da histeria.

Freud disse em 1922 que as tendências homossexuais eram intrinsecamente relacionadas com o complexo de Édipo e com as idéias de castração. A observação freudiana é de que, entre outros fatores, a ausência do pênis, na mulher, poderia ser um importante aspecto quando se considerava a questão da homossexualidade. Isto é significativo por causa do lugar ocupado pelo órgão masculino, na teoria freudiana. Esta observação significa que qualquer tipo de neurose pode desenvolver-se após a fase de castração. Assim, é impossível Ignorar os aspectos neuróticos que estão ligados à homossexualidade.

Em um estudo de 1990, Nasio (1991) demonstrou alguma relação entre homossexualidade e histeria. Para ele, a histeria leva a uma dificuldade em assumir uma indefinição sexual, mais precisamente, uma incerteza sexual.

As dificuldades ilustradas pela carta de Alexis podem associar-se a aspectos da histeria. Mesmo hoje, quando a sociedade parece acreditar na existência natural de um terceiro gênero, homossexuais encaminhamse ainda aos consultórios clínicos, solicitando ajuda.

Da perspectiva psicanalítica, um tipo de ajuda poderia ser focalizar não a homossexualidade em si, mas os componentes histéricos 
as neuroses, ajudando assim pacientes a atravessarem esta fase de suas vidas com menos ansiedade sofrimento, resultando numa re-elaboração da ansiedade de castração.

A confissão de Alexis à sua esposa evidencia sua incerteza e indecisão a respeito de sua identidade sexual. Seria o caso de perguntarmos se poderíamos todos afirmar nossa identidade sexual sem algumas dessas mesmas indecisões e incertezas.

\section{REFERÊNCIAS BIBLIOGRÁFICAS}

1. DELLAMORA, R. 1992. "Representation and homophobia in: The picture of Dorian Grey", in: Homosexual themes in literary studies, vol. VIII. New York and London: Garland.
2. FREUD, S. (1922/1976). Alguns mecanismos neuróticos no ciúme, paranóia e homossexualidade. ESB, Vol.XVIII, Rio de Janeiro, Imago.

3. HARRIS, D. 1993. "Introduccion", in Garcia Lorca, F. El publico. Madrid: Taurus.

4. LASCH, C. 1987. O mínimo eu. São Paulo, Brasiliense.

5. LORCA, F.G. 1993. El publico. Madrid:Taurus.

6. NASIO, J.-D. 1991. A histeria: teoria e clínica psicanalítica. Rio de Janeiro, Jorge Zahar.

7. SENNET, R. 1988. O declínio do homem público. São Paulo, Companhia das Letras.

8. TRILLAT,E. 1991. História da histeria. São Paulo, Escuta.

9. YOURCENAR, M. 1971. Alexis ou o tratado do vão combate. Rio de Janeiro, Nova Frontreira. 